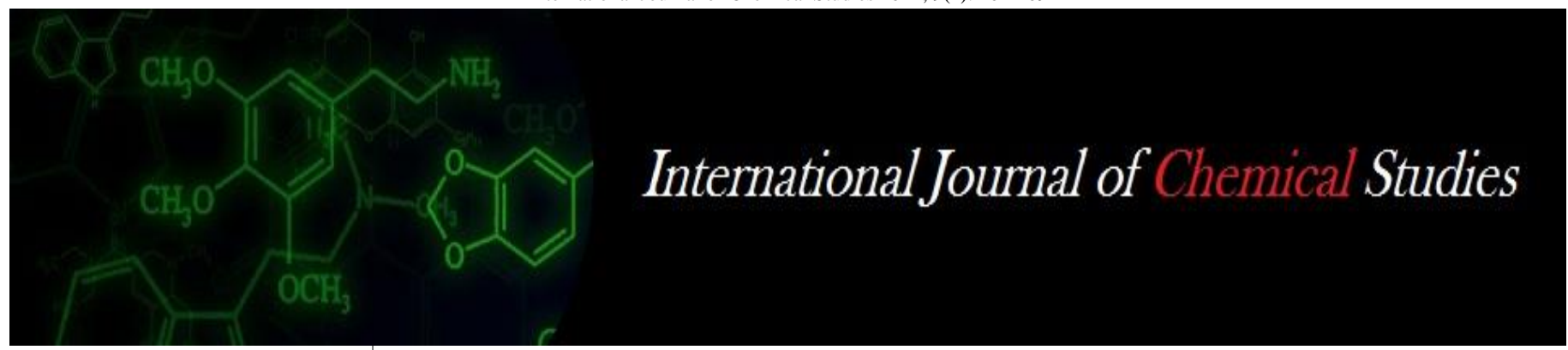

P-ISSN: 2349-8528

E-ISSN: 2321-4902

www.chemijournal.com

IJCS 2021; 9(1): 404-409

(C) 2021 IJCS

Received: 08-10-2020

Accepted: 13-11-2020

\section{Laxmi Pandey}

Department of Food Science and Nutrition, College of Community and Applied Sciences, Maharana Pratap University of Agriculture and Technology, Udaipur,

Rajasthan, India

\section{Renu Mogra}

Department of Food Science and Nutrition, College of Community and Applied Sciences, Maharana Pratap University of Agriculture and Technology, Udaipur,

Rajasthan, India

\section{Arun Goel}

Department of Dairy and Food Chemistry, College of Dairy and Food Technology, Maharana Pratap University of Agriculture and Technology, Udaipur,

Rajasthan, India
Corresponding Author: Laxmi Pandey

Department of Food Science and Nutrition, College of Community and Applied Sciences, Maharana Pratap University of Agriculture and Technology, Udaipur,

Rajasthan, India

\section{Assessment of physico-chemical properties of antioxidant rich fruits and sensory attributes of jamun based RTS beverages}

\author{
Laxmi Pandey, Renu Mogra and Arun Goel
}

DOI: https://doi.org/10.22271/chemi.2021.v9.i1f.11261

\begin{abstract}
In present investigation, efforts have been made to assess physico-chemical properties of jamun and lemon fruit and to prepare antioxidant rich ready-to-serve (RTS) beverages from jamun and lemon juice blends. The physical properties like color and shape of jamun fruit was blackish purple and ovoid or round in shape. The average length, breadth and weight of jamun fruit were $3.16 \mathrm{~cm}, 2.17 \mathrm{~cm}$ and $10.7 \mathrm{~g}$ respectively while pulp weight, seed weight, inedible waste weight and juice content were $7.45,2.46$, 0.79 and $2.31 \mathrm{~g}$ of overall fruit weight. The calculated value of edible and waste index was 69.63 and $30.37 \%$, respectively while juice yield was $21.67 \%$ of the total fruit weight. Physical properties of lemon fruit was light yellow in color and round in shape. The mean value of length, breadth and weight was $4.1 \mathrm{~cm}, 3.8 \mathrm{~cm}$ and $23.0 \mathrm{~g}$, respectively. The weight of pulp, seed, peel and juice content was $8.71,0.58$, 13.72 and $7.67 \mathrm{~g}$, respectively of overall fruit weight. The edible and waste index was 37.85 and $62.15 \%$ whereas juice yield was $33.35 \%$ of total fruit weight. The experiment comprised of six treatments including one control and five blended RTS beverages. Among different blended ratios (100:0, 99:1, 98:2, 97:3, 96:4 and 95:5) of jamun and lemon juice for preparation of RTS beverages, the ratio 97:3 was reached the highest sensory scores for overall acceptability.
\end{abstract}

Keywords: Jamun, lemon, blended RTS beverage, physical properties, overall acceptability

\section{Introduction}

India is origin of many fruit crops and most of crops is limited to its growing region only. In spite of their high nutritional and medicinal properties their commercial cultivation is lacking. Most of underutilized fruits are in the core recipes of many ayurvedic formulations and jamun is one of the most important underutilized fruit. India ranks second in production of jamun in the World. Maharashtra State is the largest jamun producer followed by Uttar Pradesh, Tamil Nadu, Gujarat, Assam and others. In India, basically two types of Syzygium (Jamun) are found, firstly, Ra Jamun which have large, oval shaped fruits, dark-purple or bluish colored with pink pulp that is sweet to taste and small seeds; secondly, Kaatha with small, acidic fruits. It has been observed that fruits containing purple flesh are more astringent than the white-fleshed types (Ranjan et al., 2011) ${ }^{[24]}$. The fruit, its juice and seed contain a biochemical called "Jamboline" and are gaining popularity due to its delicious taste, detoxifying and antioxidant properties. Besides antioxidant property, it has hyperlipidemic, cardioproptective and immunomodulatory properties. The detoxifying property of jamun helps to maintain natural urination and sweating. Jamun (Syzygium cumini) decoction is being used as Ayurvedha medicine in diabetes mellitus, because it has high antiglycation and antioxidant activities. Therefore, the antiglycation and antioxidant potentials of a ready to serve herbal beverage prepared with the water extract of Syzygium cumini bark targeting the diabetic population as this may have a better therapeutic potential. Jamun juice can be supplemented with lemon and aonla juice to increase its antioxidant property by increasing vitamin $\mathrm{C}$ and micronutrient levels.

Lemon (Citrus limon) is a therapeutic plant belonging to the family of Rutaceae. It is a small tree and originated probably from Asia. It used in making various foods, due to its distinctive flavor and ability to enhance spicy flavor in food products. Lemon juice is very rich in vitamin $\mathrm{C}$, a vitamin act as an antioxidant and responsible for health benefits. It has anticancer and antibacterial potential in crude extracts of different parts (viz. leaves, stem, root and flower) 
of Lemon against bacterial strains. Beverages are prepared using lemon juice, considered to be an excellent source of nutraceutical components for enrichment. Blending could lead to the production of delicious beverages with improve organoleptic quality and high nutritive value. The nutritive value of fruit beverages is higher than the synthetic drinks, which are available in the market throughout the country. If synthetic drinks can be substituted with the fruit juice, it would be beneficial to the consumers as well as fruit growers. The usage of various synthetic/natural sweeteners in lieu of sugar is increasing day by day due to health concerns. In India, use of artificial sweeteners is limited but being economical, it is helpful to control different kind of degenerative diseases. A variety of artificial sweeteners are available in the market like, aspartame, cyclamate, sucralose, saccharin, and acesulfame-K (Pottasium salt of Acesulfame) etc. These are the non-nutritive sweeteners which are not metabolized by the body and do not contribute any energy or calories to the diet. The use of low-calorie sweeteners could improve dietary quality if consumers used energy savings for the consumption of nutrient dense foods (ADA, 2004) ${ }^{[4]}$. Therefore, the aspartame can be used as a low calorie sweetener for developing functional ready-to-serve beverage, which will be an alternative way of consumption apart from regular traditional preparations.

Based on these concepts the experiment was undertaken to develop antioxidant rich blended ready-to-serve (RTS) beverage with the following objectives-

- To assess physico-chemical properties of jamun and lemon fruits

- To standardized antioxidant rich jamun based ready-toserve (RTS) beverages

- To evaluate sensory quality of developed ready-to-serve (RTS) beverages

\section{Material and Methods}

The present investigation was carried out at Department of Food Science and Nutrition, College of Community and Applied Sciences, MPUAT, Udaipur (Rajasthan). The jamun and lemon fruits used for investigation procured from the local market. Fresh, disease free and uniform sized jamun and lemon fruits were sorted washed in running tap water and cut with knife for removal of seed. Jamun fruit were pulped with the help of mixer cum grinder and pulp $20 \%$ were taken to get jamun juice with addition of $80 \%$ double distilled water while lemon fruits were cut into two halves and tightly griped for squeezing the juice by hand press method. The juice was filtered through four layer muslin cloth to get clear juice. The fresh extracted jamun and lemon juice was used for preparation of jamun based ready-to-serve (RTS) beverages.

\section{Development of antioxidant rich jamun based ready-to- serve (RTS) beverages \\ Mixing the ingredients}

Antioxidant rich jamun based ready-to-serve beverages were developed by blending the juices in five different formulations of jamun and lemon juices, 99:1 $\left(\mathrm{T}_{1}\right)$, 98:2 $\left(\mathrm{T}_{2}\right)$, 97:3 $\left(\mathrm{T}_{3}\right)$, 96:4 $\left(\mathrm{T}_{4}\right)$ and 95:5 $\left(\mathrm{T}_{5}\right)$ respectively, while pure jamun ready-to-serve beverage formulated using jamun and lemon in the ratio of 100:0. The pulp/juice content was adjusted 20\%, TSS $15 \%$ and acidity $0.3 \%$ for the development of beverages. Meanwhile, black salt added for enhancing the taste at the time of formulation of juice blends. Refined cane sugar was added as sweetening agent for enhancing the taste and zero calorie sweetener aspartame (based on sugar equivalents) were used for the development of low calorie jamun based RTS beverages. The acidity was maintained to $0.3 \%$ in the final product by the addition of required amount of citric acid (Table 1).

\section{Filtration}

The developed carrot based RTS beverages were again filtered through a muslin cloth to obtain a beverage of uniform consistency.

\section{Pasteurization}

The developed jamun based RTS beverages were pasteurized at $90{ }^{\circ} \mathrm{C}$ for $30 \mathrm{sec}$. and cooled at room temperature.

Table 1: Formulations of antioxidant rich jamun based ready-to-serve beverages

\begin{tabular}{|c|c|c|c|c|c|c|c|c|}
\hline \multirow{2}{*}{ Sr. No. } & \multirow{2}{*}{ Treatment symbols } & \multicolumn{2}{|c|}{ Blending of juices (\%) } & \multirow{2}{*}{ Rock salt (g) } & \multirow{2}{*}{$\begin{array}{l}\text { Non-calorie sweetener } \\
\text { (Aspartame) } \%\end{array}$} & \multirow{2}{*}{ Sugar $(g)$} & \multirow{2}{*}{$\begin{array}{l}\text { Citric acid } \\
(\mathrm{g})\end{array}$} & \multirow{2}{*}{$\begin{array}{c}\text { Sodium } \\
\text { benzoate }(\mathrm{g})\end{array}$} \\
\hline & & Jamun & Lemon & & & & & \\
\hline 1. & Control $\left(\mathrm{T}_{0}\right)$ & 100 & 0 & 1.25 & 0.2 & 5.0 & 0.2 & 0.05 \\
\hline 2. & $\mathrm{JL1}\left(\mathrm{T}_{1}\right)$ & 99 & 1 & 1.25 & 0.2 & 5.0 & 0.2 & 0.05 \\
\hline 3. & $\mathrm{JL2}\left(\mathrm{T}_{2}\right)$ & 98 & 2 & 1.25 & 0.2 & 5.0 & 0.2 & 0.05 \\
\hline 4. & $\mathrm{JL} 3\left(\mathrm{~T}_{3}\right)$ & 97 & 3 & 1.25 & 0.2 & 5.0 & 0.2 & 0.05 \\
\hline 5. & JL4 $\left(T_{4}\right)$ & 96 & 4 & 1.25 & 0.2 & 5.0 & 0.2 & 0.05 \\
\hline 6. & JL5 ( $\left.\mathrm{T}_{5}\right)$ & 95 & 5 & 1.25 & 0.2 & 5.0 & 0.2 & 0.05 \\
\hline
\end{tabular}

Where JL - Jamun \& lemon

\section{Physical properties of fruits}

Physical Characteristics like color and shape was observed visually. Fruit weight (in grams) was determined using a digital electronic balance while length and breadth measured with the help of a digital vernier caliper. The edible index, waste index and juice content were determined by the method given by Shamsudin et al., $2009^{[27]}$.

\section{Chemical properties}

The physico-chemical properties of the jamun and lemon fruits were analyzed using recommended standard methods.

Moisture content: The moisture content of the fruits was determined by gravimetric method (AOAC, 2012) ${ }^{[1,2,3]}$.
Specific gravity: Specific gravity was determined by weight of fruit divided by volume of fruit.

\section{Total solids}

Total solids were estimated by deducting percentage moisture from 100 as described by James (1995) ${ }^{[14]}$.

\section{Total soluble solids}

The total soluble solids (TSS) of the fruits were determined by the standard method (AOAC, 2012) ${ }^{[1,2,3]}$.

\section{pH}

For determination of $\mathrm{pH}$ (hydrogen ion concentration) in the juice, a method of AOAC (2000) ${ }^{[1,2,3]}$ was adopted. 


\section{Titrable acidity}

Titrable acidity was determined by titrating a known volume of the sample against $\mathrm{N} / 10 \mathrm{NaOH}$ solution using phenolphthalein as an indicator. The titrable acidity was calculated and expressed as pcent citric acid (AOAC, 2000) ${ }^{[1,}$ $2,3]$.

\section{Total and reducing sugar}

The total and reducing sugars were estimated by the volumetric method of Lane and Eynon (1923) as reported by Ranganna (1986).

\section{Total carotenoids}

Total carotenoid content of fruit pulp/juices were determined spetrophotometrically by slight modification of method described by Rodriguez-Amaya (2004) ${ }^{[25]}$.

\section{Ascorbic acid}

The ascorbic acid content of fruit pulp/juices were estimated by using 2-6 dichlorophenol-indophenol (dye) visual titration method with slight modification of the method given by Ranganna (2014).

\section{Total antioxidant activity}

The percentage of 2, 2-diphenyl-1-picrylhydrazyl (DPPH) radical scavenging activities of fruit pulp/juices and RTS drink was determined by the slight modification of the spectrophotometric method as suggested by Shimada et al. (1992) [28, 29]

\section{Sensory evaluation of jamun based ready-to-serve beverages}

A panel of ten judges comprising of the staff and research scholars were randomly selected from the Department of Food Science and Nutrition, College of Home Science, MPUAT, Udaipur for the evaluation of acceptability of the ready-to serve (RTS) beverages developed during the study. Coded samples were presented to panellist in separate chambers or places to get unbiased judgments with score cards for evaluating the sensory characteristics. The overall acceptability was measured on 9 point Hedonic Scale by 10 panel members.

\section{Statistical analysis}

The data generated during experimentation were recorded and statistically analyzed using standard procedure for analysis of completely randomized block design (CRD) as per the method suggested by (Panse and Sukhatme, 1985) ${ }^{[21]}$.

Mean \pm SD for physico-chemical properties of juices and ready-to-serve beverages. Analysis of variance (One way ANOVA) was used to assess sensory acceptability scores of antioxidant rich ready-to-serve beverages, were calculated.

\section{Results and Discussion \\ Physical properties of jamun and lemon fruit \\ Jamun}

The physical properties of jamun and lemon fruit was observed and presented in Table 2 .

The data depicted the result of physical properties of jamun fruit in Table 2. The color and shape of jamun fruit was blackish purple and ovoid or round in shape. The average length and breadth of jamun fruit was 3.16 and $2.17 \mathrm{~cm}$, respectively. Similar observations were recorded by Shahnawaz and Sheikh (2011) ${ }^{[26]}$ that indigenous jamun fruit cultivar was ovoid in shape and blackish-purple in color. The length and width of indigenous fruit cultivars was 2.73 and $2.10 \mathrm{~cm}$, respectively. The result showed that the overall fruit weight of jamun was recorded $10.7 \mathrm{~g}$, while pulp, seed and inedible waste had $7.45,2.46$ and $0.79 \mathrm{~g}$ weight of overall fruit weight. The fruit had $2.31 \mathrm{~g}$ juice content, which was $21.67 \%$ juice yield of the total fruit weight. The calculated value of edible and waste index was 69.63 and $30.37 \%$, respectively.

The variations in the physical properties of jamun fruit might be due to varietal differences, species, rootstock used, edapho-climatic conditions of growing, agro inputs applied to the trees bearing that fruit. The market value of the fruit depends on the weight and the color of the fruit. The maturity of the fruit was determined by the dimension of the fruit. Similar results were also reported by Shahnawaz and Sheikh (2011) ${ }^{[26]}$ analyzed physical properties of indigenous fruit cultivar and found fruit weight was $6.71 \mathrm{~g}$, whereas edible matter/pulp, non-edible matter/seed and juice 39.19, 60.81 and $38 \%$, respectively of whole fruit weight. Ghosh et al. (2017) [11] reported weight of the whole fruit was $8.99 \pm 1.89 \mathrm{gm}$. The whole fruit length, width and thickness was $28.1 \pm 0.31,22.7 \pm 0.14,20.8 \pm 0.21 \mathrm{~mm}$ respectively From the yield recovery, it was observed that the whole fruit had 79.81 and $19.25 \%$ consumable and non-consumable portion (seed). The juice yield from the consumable portion was measured as $54.1 \%$.

Table 2: Physical properties of jamun and lemon fruit

\begin{tabular}{|c|c|c|}
\hline Physical properties & Jamun & Lemon \\
\hline Color & Blackish-purple & Light yellow \\
\hline Shape & Ovoid/round & Round \\
\hline Length $(\mathrm{cm})$ & $3.16 \pm 0.01$ & $4.1 \pm 0.02$ \\
\hline Breadth $(\mathrm{cm})$ & $2.17 \pm 0.01$ & $3.8 \pm 0.01$ \\
\hline Weight $(\mathrm{g})$ & $10.7 \pm 0.04$ & $23.0 \pm 0.05$ \\
\hline Pulp weight $(\mathrm{g})$ & $7.45 \pm 0.03$ & $8.71 \pm 0.04$ \\
\hline Seed weight $(\mathrm{g})$ & $2.46 \pm 0.01$ & $0.58 \pm 0.01$ \\
\hline Peel weight $(\mathrm{g})$ & - & $13.72 \pm 0.04$ \\
\hline Inedible waste $(\mathrm{g})$ & $0.79 \pm 0.01$ & - \\
\hline Juice content $(\mathrm{g})$ & $2.31 \pm 0.01$ & $7.67 \pm 0.04$ \\
\hline Edible index $(\%)$ & $69.63 \pm 0.10$ & $37.85 \pm 0.09$ \\
\hline Waste index $(\%)$ & $30.37 \pm 0.07$ & $62.15 \pm 0.11$ \\
\hline Juice yield $(\%)$ & $21.67 \pm 0.12$ & $33.35 \pm 0.08$ \\
\hline
\end{tabular}

Mean \pm SD of three independent variables

\section{Lemon}

Physical properties of lemon fruit under the study presented in Table 2. Data with respect to physical properties revealed that lemon fruit was light yellow in color and round in shape. The mean value of length and breadth was 4.1 and $3.8 \mathrm{~cm}$, respectively. The average weight of lemon fruit was $23.0 \mathrm{~g}$. However, the weight of pulp, seed, peel and juice content was $8.71,0.58,13.72$ and $7.67 \mathrm{~g}$, respectively of overall fruit weight. The mean value of edible and waste index was 37.85 and $62.15 \%$, whereas juice yield was calculated as $33.35 \%$ of total fruit weight.

These results were in the conformity with Mansoor et al. (2018) found that highest individual fruit weight of orange, lemon and grapefruit remained 222.26, 22.11 and 295.21g, respectively. The highest peel $(\%)$ was obtained in orange $27.90 \%\left(\mathrm{~T}_{2}\right)$, lemon $18.28 \%\left(\mathrm{~T}_{1}\right)$, while in grapefruit it was $26.79 \%\left(\mathrm{~T}_{1}\right)$. Highest pulp $(\%)$ for orange fruit $27.09 \%\left(\mathrm{~T}_{3}\right)$, However, lemon and grapefruit showed highest pulp 27.34 $\left(\mathrm{T}_{3}\right)$ and $27.04 \%\left(\mathrm{~T}_{3}\right)$, respectively. The highest juice \% was obtained as $55.75 \%\left(\mathrm{~T}_{2}\right)$ for orange, $47.26 \%\left(\mathrm{~T}_{1}\right)$ for lemon and $44.84 \%\left(\mathrm{~T}_{2}\right)$ for grapefruit. 


\section{Physico-chemical properties of jamun and lemon juice}

The data for physic-chemical properties of jamun and lemon are presented in Table 3 .

\section{Jamun juice}

The data revealed that freshly extracted jamun juice had physical properties viz. moisture $(82.90 \%)$, specific gravity (1.27) and total solids (17.09\%). Among the chemical properties of fresh jamun juice, the mean value of total soluble solids, $\mathrm{pH}$ and titrable acidity were $14.1^{\circ} \mathrm{Brix}, 3.82$ and $1.59 \%$, respectively (Table 3). Similar findings were reported by Kesharwani et al. (2015), Ghosh et al. (2017) ${ }^{[11]}$, Akhila and Umadevi (2018) ${ }^{[5]}$ and Lavanya et al. (2018) ${ }^{[18]}$. The results that jamun juice contained $12.60 \%$ total sugar, $5.92 \%$ reducing sugar and $6.96 \%$ non-reducing sugar. The results are in agreement with the previous findings of Barman and Barooah (2016) ${ }^{[6]}$, who reported that fresh jamun juice had total sugar $(13.92 \mathrm{~g} / 100 \mathrm{~g})$ and reducing sugar (5.59 g/100g). Similarly, Devi (2002), Barman and Barooah (2016) [6], Akhila and Umadevi (2018) ${ }^{[5]}$ and Lavanya et al. (2018) [18] observed that jamun juice contained total, reducing and non-reducing sugars between the ranges of $(12.60-14.22 \%)$, $(5.70-8.90 \%)$ and $(3.07-8.90 \%)$ respectively.

Some bioactive compounds viz. total carotenoid, ascorbic acid and total antioxidant activity were $0.078 \mathrm{mg} / 100 \mathrm{~g}, 29.94$ $\mathrm{mg} / 100 \mathrm{~g}$ and $90.71 \%$ respectively in jamun juice (Table 3 ). The carotenoids are natural pigment that give both appearance and attractiveness to beverages as well as add nutritional value due to antioxidant activity. The result regarding ascorbic acid of fresh jamun juice was in agreement with
Lago et al 2004 who reported that jamun juice contains ascorbic acid $18 \mathrm{mg} / 100 \mathrm{~g}$. Similarly other researchers Kesharwani et al. (2015), Panda et al. (2016) ${ }^{[20]}$, Ghosh et al. (2017) ${ }^{[11]}$ and Lavanya et al. (2019) observed 31.5\%, 31.8 $\mathrm{mg} / 100 \mathrm{~g}, 49.78 \mathrm{mg} / 100 \mathrm{~g}$ and $19.0 \mathrm{mg} / 100 \mathrm{~g}$ ascorbic acid in fresh jamun juice. The result showed total antioxidant activity of fresh jamun juice was $90.71 \%$ scavenging of DPPH, which are in agreement with findings of Barman and Barooah (2016), Ghosh et al. (2017) [11] and Akhila and Umadevi (2018) [5] reported that fresh jamun juice contained total antioxidant activity of $92.20 \%, 31.29 \%$ and $92.0 \%$ scavenging of DPPH, respectively.

Table 3: Physico-chemical properties of jamun and lemon juice

\begin{tabular}{|c|c|c|}
\hline Physical properties & Jamun juice & Lemon juice \\
\hline Moisture (\%) & $82.90 \pm 0.05$ & $93.08 \pm 0.07$ \\
\hline Specific Gravity & $1.27 \pm 0.02$ & $0.23 \pm 0.01$ \\
\hline Total solids (\%) & $17.09 \pm 0.04$ & $7.08 \pm 0.03$ \\
\hline \multicolumn{3}{|c|}{ Chemical properties } \\
\hline TSS ( ${ }^{\circ}$ Brix $)$ & $14.10 \pm 0.03$ & $7.02 \pm 0.02$ \\
\hline Titrable acidity $(\%)$ & $1.59 \pm 0.01$ & $5.17 \pm 0.02$ \\
\hline $\mathrm{pH}$ & $3.82 \pm 0.02$ & $1.52 \pm 0.01$ \\
\hline Total sugar $(\%)$ & $12.60 \pm 0.04$ & $1.42 \pm 0.02$ \\
\hline Reducing sugar (\%) & $5.92 \pm 0.02$ & $0.56 \pm 0.01$ \\
\hline Non-reducing sugar $(\%)$ & $6.96 \pm 0.04$ & $0.86 \pm 0.02$ \\
\hline Ascorbic acid (mg/100ml) & $29.94 \pm 0.06$ & $43.21 \pm 0.09$ \\
\hline Total carotenoids $(\mathrm{mg} / 100 \mathrm{ml})$ & $0.078 \pm 0.01$ & - \\
\hline Total antioxidant activity (\%) & $90.71 \pm 0.11$ & $76.80 \pm 0.09$ \\
\hline
\end{tabular}

Mean \pm SD of three independent variables

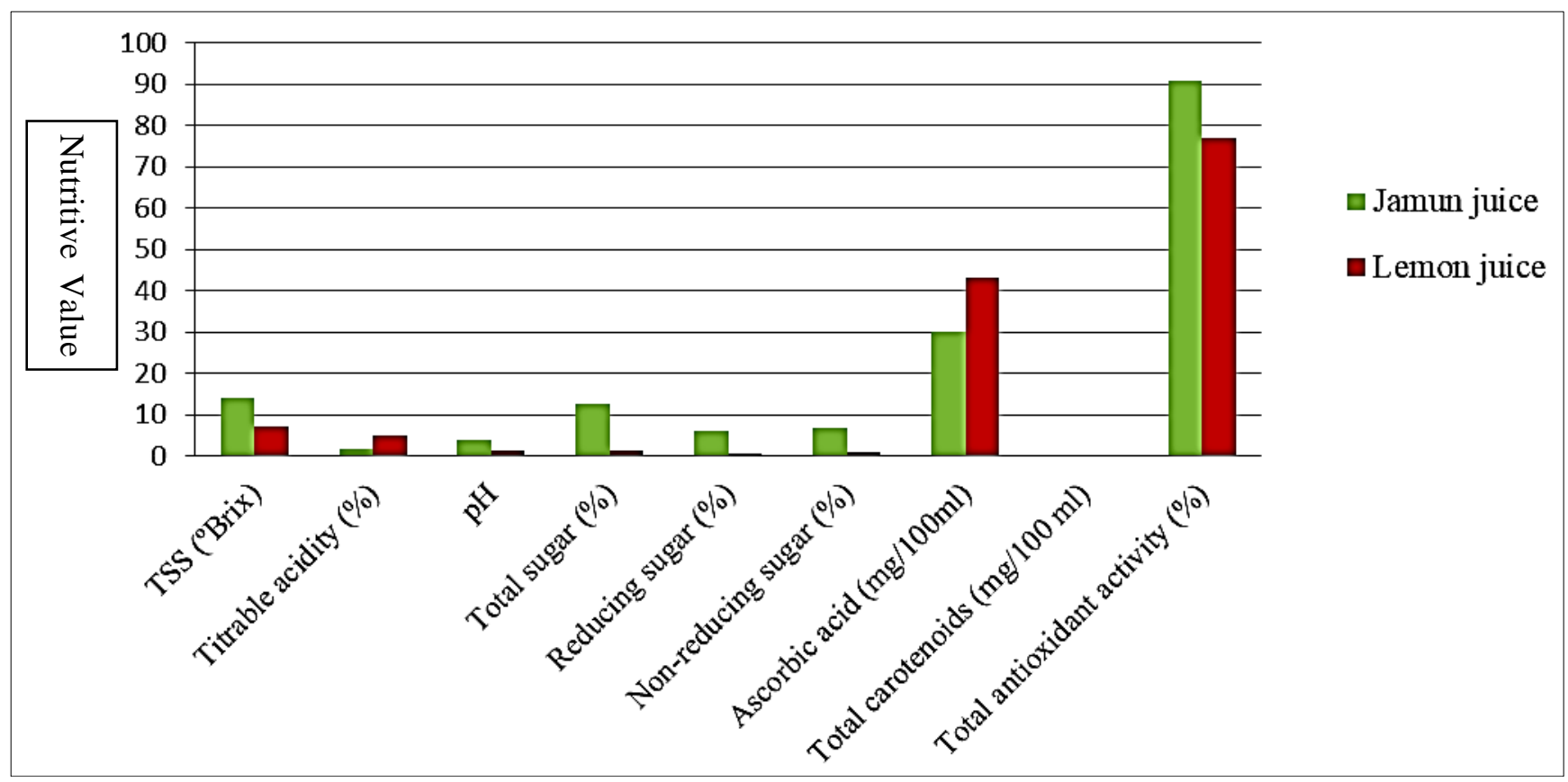

Fig 1: Physico-chemical properties of jamun and lemon juice

\section{Lemon juice}

The data revealed that freshly extracted lemon juice had physical properties viz. moisture (93.08\%), specific gravity (0.23) and total solids $(7.08 \%)$. Among the chemical properties of fresh lemon juice, the mean value of total soluble solids, $\mathrm{pH}$, titrable acidity, total sugar, reducing sugar and non-reducing sugars were $7.02^{\circ}$ Brix, $1.52,5.17 \%, 1.42 \%$, $0.56 \%$ and $0.86 \%$ respectively (Table 3 ). Similar findings were reported by Deka (2000) ${ }^{[7]}$ analyzed physico-chemical properties viz. moisture $(92.55 \%)$, total soluble solids
(8.35 ${ }^{\circ}$ Brix), titrable acidity $(6.78 \%), \mathrm{pH}(2.24)$, total sugar $(1.12 \%)$ and reducing sugar $(0.61 \%)$ respectively. Similarly Jain and Khurdiya (2004) [13] reported physico-chemical properties were $7.0^{\circ}$ Brix total soluble solids, $5.76 \%$ acidity and $43.29 \mathrm{mg} / 100 \mathrm{~g}$ ascorbic acid. The bioactive compounds viz. ascorbic acid and total antioxidant activity were 43.21 $\mathrm{mg} / 100 \mathrm{~g}$ and $76.80 \%$ scavenging of DPPH. The result showed there was no total carotenoid was found in lemon juice. The results were in line with observations made by Deka (2000) ${ }^{[7]}$ found fresh lemon juice that contains ascorbic 
acid $(32.40 \mathrm{mg} / 100 \mathrm{ml})$ whereas no total carotenoids was detected in lemon juice. Kumar et al. (2013) ${ }^{[16]}$ observed (40.48 mg/100g) vitamin C and Hajimahmoodi et al. (2012) [12] reported antioxidant activity $795.65 \mathrm{mg} \mathrm{VEE} \mathrm{L} \mathrm{L}^{-1}$ scavenging of DPPH in fresh lemon juice.

\section{Organoleptic acceptability of antioxidant rich jamun based RTS beverages}

The data showed mean scores of the organoleptic characteristics of jamun-lemon juice blends used for development of antioxidant rich ready-to-serve beverages (Table 4). The overall acceptability scores are very important aspects that determine the acceptability and marketability of beverages. Organoleptic evaluation of six treatments, developed in the ratio of, $\mathrm{T}_{0}$ (jamun-lemon, 100:0), $\mathrm{T}_{1}$ (jamunlemon, 99:1), $\mathrm{T}_{2}$ (jamun-ginger, 98:2) $\mathrm{T}_{3}$ (jamun-lemon,
97:3), $\mathrm{T}_{4}$ (jamun-lemon, 96:4), $\mathrm{T}_{5}$ (jamun-lemon, 95:5) and analyzed for color, appearance, flavor, consistency, taste and overall acceptability. The overall characteristics of the prepared ready-to-serve beverages were graded as "like extremely to dislike very much" with score values as $9-1$. The data indicated that the color score of different treatments of fresh jamun RTS beverages ranged from 7.80 to 8.20, appearance scores from 7.40 to 8.50 , flavor scores from 7.90 to 8.00 , consistency scores from 8.10 to 8.30 and taste score from 8.10 to 8.30 while overall acceptability scores from 7.86 to 8.26. The organoleptic scores of all the treatments differed significantly $(P \leq 0.05)$ in sensory attributes of appearance, taste and overall acceptability and fell in the category of "liked very much" to "liked extremely" while color, flavor and consistency scores showed non-significant differences among all six treatments.

Table 4: Organoleptic evaluation of antioxidant rich jamun based ready-to-serve beverages

\begin{tabular}{|c|c|c|c|c|c|c|}
\hline \multirow{2}{*}{ Treatments } & \multicolumn{7}{|c|}{ Sensory attributes } \\
\cline { 2 - 7 } & Color & Appearance & Flavor & Consistency & Taste & Overall acceptability \\
\hline $\mathrm{T}_{0}$ & $7.8 \pm 0.13$ & $7.4 \pm 0.22$ & $7.9 \pm 0.18$ & $8.1 \pm 0.10$ & $8.1 \pm 0.10$ & $7.86 \pm 0.13$ \\
\hline $\mathrm{T}_{1}$ & $7.7 \pm 0.26$ & $8.4 \pm 0.22$ & $8.0 \pm 0.21$ & $8.2 \pm 0.20$ & $8.3 \pm 0.21$ & $8.12 \pm 0.16$ \\
\hline $\mathrm{T}_{2}$ & $8.3 \pm 0.21$ & $8.5 \pm 0.16$ & $8.4 \pm 0.22$ & $8.3 \pm 0.15$ & $8.7 \pm 0.15$ & $8.44 \pm 0.15$ \\
\hline $\mathrm{T}_{3}$ & $8.4 \pm 0.16$ & $8.5 \pm 0.11$ & $8.5 \pm 0.16$ & $8.4 \pm 0.22$ & $8.9 \pm 0.10$ & $8.54 \pm 0.13$ \\
\hline $\mathrm{T}_{4}$ & $8.2 \pm 0.25$ & $8.4 \pm 0.20$ & $8.3 \pm 0.26$ & $8.3 \pm 0.26$ & $8.6 \pm 0.16$ & $8.36 \pm 0.12$ \\
\hline $\mathrm{T}_{5}$ & $8.2 \pm 0.20$ & $8.5 \pm 0.17$ & $8.0 \pm 0.25$ & $8.3 \pm 0.15$ & $8.3 \pm 0.26$ & $8.26 \pm 0.13$ \\
\hline $\mathrm{CD}(P \leq 0.05)$ & NA & 0.58 & NA & NA & 0.49 & 0.39 \\
\hline
\end{tabular}

Mean \pm SD of ten independent variables

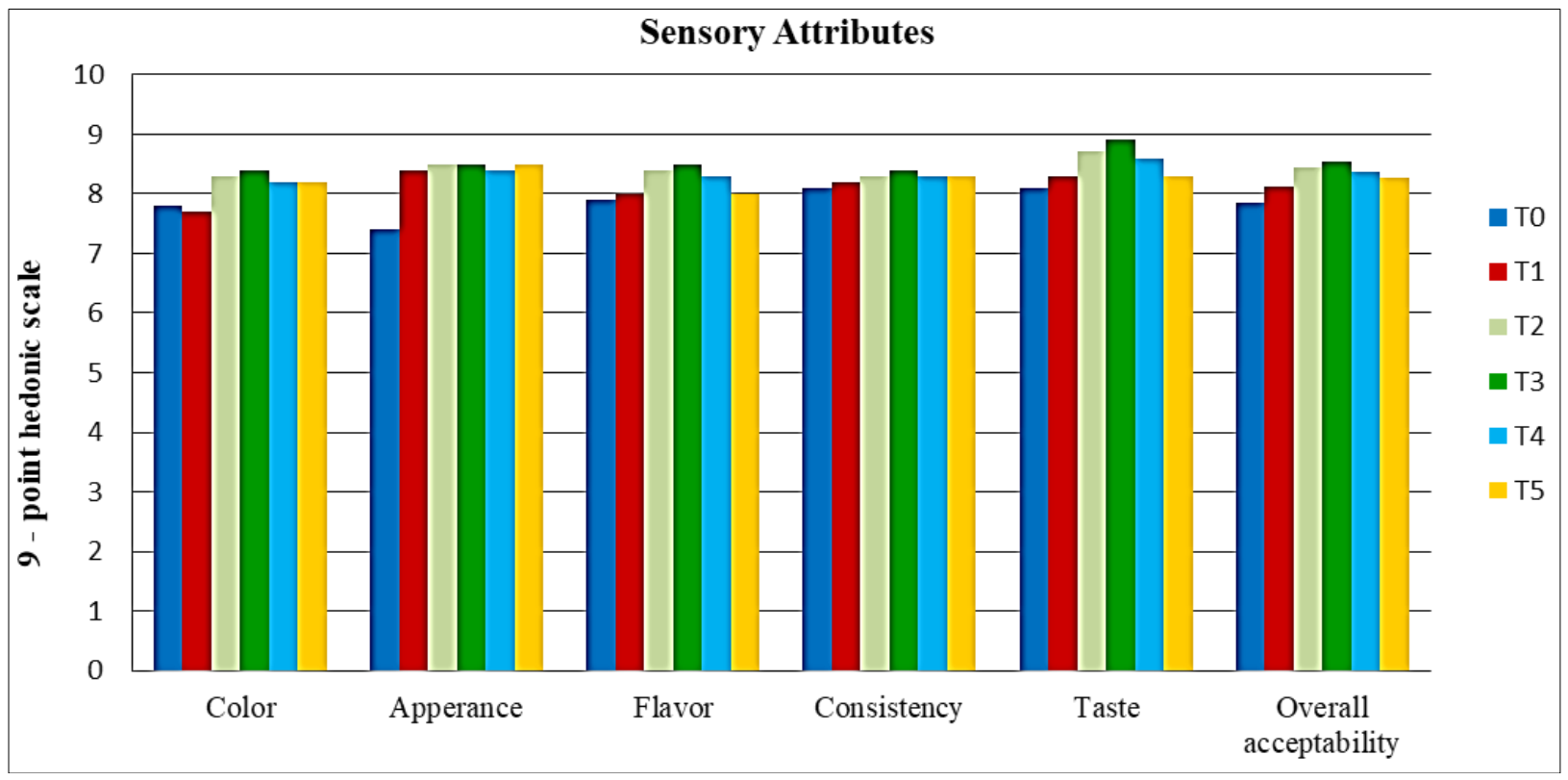

Fig 2: Organoleptic acceptability of jamun based RTS beverages

The statistical analysis of sensory scores showed significant difference for overall acceptability of jamun based RTS beverages (Table 4). Maximum mean score was attained by $\mathrm{T}_{3}$ (8.40) followed by $\mathrm{T}_{2}(8.44)$ while minimum score was recorded in sample $T_{0}$ (7.86). In the present study, results indicated that color, appearance, flavor, consistency, taste and overall acceptability of blended ready-to-serve beverages were found to be superior as the portion of lemon juice increased. The results were in agreement with the findings of Din et al. (2011) who reported that the judges concluded that decreased in level of substitution of lemon juice decreased the overall acceptability for the drinks.

Similar findings reported by Sooch et al. (1995) ${ }^{[30]}$ that blending the fruit juices of kinnow, pear and grapes with a small quantity of strongly flavoured vitamin rich fruit juice, blends can be prepared for commercial exploitation by the processing industry. However, (Deka, 2000; Deka and Sethi, 2001) ${ }^{[7,8]}$ found that two or more fruit juice / pulp may be blended in various proportions for the preparation of nectar, RTS beverages etc. The blending of juice may also improve aroma, taste and nutrients of the beverages.

\section{Conclusion}

The aim of the present study was to assess the physicochemical properties of antioxidant rich fruits and organoleptic acceptability of antioxidant rich jamun based RTS beverages. The physical properties help in development of processing technology and to minimize the effect of an inadequate use of 
equipment that could affect the quality of the fruit and its juices. Jamun and lemon fruits contain higher antioxidant activity and adequate amount of vitamin-c. Among the various developed antioxidant rich RTS beverages, blended jamun based RTS beverages (jamun-lemon, 97:3) had maximum scores of overall acceptability. Therefore, it can be concluded that jamun and lemon fruits are rich in antioxidant and medicinal properties and can be used as a valuable ingredients for the development of fruit based RTS beverages. Hence it can be proved that the standardized antioxidant rich RTS beverages could be a good addition to varieties of commercially produced health drinks. The future possibilities lies in utilizing jamun fruit juice for the production of beverages to boost nutritional requirement and to promote the utilization of minor fruit crops.

\section{References}

1. AOAC. Official Methods of Analysis. Association of Official Analytical Chemists. Washington, D.C. 16th edition 2000.

2. AOAC. Official method of analysis. (19th edn.) The Association for Official Analysis in Chemistry, Rockwille, USA 2012.

3. AOAC. Official Methods of Analysis. Association of Official Analytical Chemists. Washington, D.C. 19th edition 2014

4. ADA. American Dietetic Association. Position of the American Dietetic Assn.: Use of nutritive and non nutritive sweeteners. Journal of American. Diet Association 2004;104:255-75.

5. Akhila H, Umadevi SH. Storage effects on vitamin c, anthocyanins, total phenolic and antioxidant capacity of processed jamun fruit products. International Journal of Pure and Applied Bioscience 2018;6(6):1335-1347.

6. Barman N, Barooah MS. Development of Functional RTS Beverage from Jamun (Syzygium cumini L.) and Melastoma malabathricum. Journal of Agricultural Engineering and Food Technology 2016;3(4):293-298.

7. Deka BC. Preparation and storage of mixed fruit juice spiced beverage, 2000 Ph.D. Thesis, IARI, New Delhi 2000.

8. Deka BS, Sethi V, Prasad R, Batra PK. Application of mixtures methodology for beverages from mixed fruit juice/pulp. Journal of Food Science and Technology 2001;38(6):615-618.

9. Devi SP, Thangam M, Desai AR, Adsule PG. Studies on variability in physico-chemical characters of different jamun (Syzygium cumini) accessions from Goa. Indian Journal of Horticulture 2002;59(2):153-156.

10. Din A, Bukhari SAH, Salam A, Ishfaq B. Development of functional and dietetic beverage from bitter gourd. International Journal of Food Safety 2011;13:355360.

11. Ghosh P, Pradhan RC, Mishra S, Patel AS, Kar A. Physicochemical and Nutritional Characterization of Jamun (Syzygium Cuminii). Current Research of Nutrition and Food Science 2017;4(2):1-11.

12. Hajimahmoodi M, Aliabadipoor M, Moghaddam G, Sadeghi N, Oveisi MR, Jannat B. Evaluation of in vitro antioxidant activities of lemon juice for safety assessment. American Journal of Food Technology 2012;7(11):708-714.

13. Jain SK, Khurdiya DS. Vitamin C enrichment of fruit juice based ready-to-serve beverages through blending of Indian gooseberry (Emblica officinalis
Gaertn.) juice. Plant Foods for Human Nutrition 2004;59(2):63-64.

14. James CS. Analytical Chemistry of Foods. $1^{\text {st }}$ Edition, Chapman and Hall, New York, ISBN: 978-1-4613-59050 1995, P178.

15. Kesharwani A, Dikshit SN, Kumar K, Thakur P, Chandel N. Studies on physico-chemical composition of jamun and changes in chemical composition of RTS beverage during storage. An International Quarterly Journal of Environmental Science 1995;7:379-383.

16. Kumar V, Singh SK. Quality and evaluation of banana and kinnow fruit based RTS beverage as influenced by blending ratio and their storage study at different conditions. International Journal of Agricultural Engineering 2013;6(2):409-414.

17. Lago ES, Gomes E, da Silva R. Extraction and anthocyanin pigment quantification of the Jamun fruit (Syzygium cumini Lam) 2004.

18. Lavanya T, Raj D, Vaghashiya JM. Standardization of formulation for preparation of health drink by blending Aloe vera, Guava and Jamun. International Journal of Chemical Studies 2018;6(4):1715-1721.

19. Mansoor B, Sawate AR, Patil BM, Kshirsagar RB. Studies on development of low calorie pineapple RTS beverage by using artificial sweeteners. Food Science Research Journal 2018;8(1):59-63.

20. Panda B, Sharma HG, Bisen B. Recipe standardization and storability of jamun RTS with alternative sweeteners. International Journal of Current Microbiology and Applied Science 2019;8(1):1731-1742.

21. Panse VG, Sukhatme PV. Statistical method for agricultural workers. Indian Council of Agricultural Research, New Delhi 1985.

22. Rangana S. Handbook of analysis and quality control of fruit and vegetable products. Tata McGraw-Hill Education 1986.

23. Rangana S. Handbook of analysis and quality control for fruit and vegetable products. Tata McGraw-Hills publishing Co. Ltd.., New Delhi 2014.

24. Ranjan A, Jaiswal A, Raja RB. Enhancement of Syzygium cumini (Indian jamun) active constituents by ultra-violet (UV) irradiation method. Scientific Research and Essays 2011;6(12):2457-2464.

25. Rodriguez-Amaya DB, Kimura M. Harvest Plus handbook for carotenoid analysis. International Food Policy Research Institute and International Centre for Tropical Agriculture. Washington DC 2004.

26. Shahnawaz M, Sheikh SA. Physicochemical characteristics of jamun fruit. Journal of Horticulture and Forestry 2011;3(10):301-306.

27. Shamsudin R, Daud WRW, Takriff MS, Hassan O. Physicochemical Properties of the Josapine Variety of Pineapple Fruit. International Journal of Food Engineering 2007;3(5):1-12.

28. Shimada K, Fujikawa K, Yahara K, Nakamura T. Antioxidant properties of xanthan on the antioxidation of soybean oil in cyclodextrin emulsion. Journal of Agricultural and Food Chemistry 1992;40:945-948.

29. Shimada K, Fujikawa K, Yahara K, Nakamura T. Antioxidant properties of xanthan on the antioxidation of soybean oil in cyclodextrin emulsion. Journal of Agricultural and Food Chemistry 1992;40:945-948.

30. Sooch HS, Sandhu KS, Sandhu JS. A juicy affair. Food Technology 1995;13(2):27-31. 